\title{
Correction to: Design of Wideband CIC Compensator Based on Particle Swarm Optimization
}

\author{
Linsen $\mathrm{Xu}^{1} \cdot$ Wei Yang ${ }^{1} \cdot$ Hongxian $\operatorname{Tian}^{1}$ \\ Published online: 3 May 2019 \\ ๑) Springer Science+Business Media, LLC, part of Springer Nature 2019
}

\section{Correction to: Circuits, Systems, and Signal Processing (2019) 38: 1833-1846 https://doi.org/10.1007/s00034-018-0947-9}

Authors of this article [5] were not aware of the work by Romero and Jimenez [4] and would like to clarify the differences below:

1. The main work of our article is the improvement in integer programming for compensator design. Different bit-lengths of fractional part are simulated when we compare proposed compensators with Dolecek et al. [1] and Molnar et al. [3], and we discussed the impact on optimum passband deviation caused by different bit-lengths of fraction part (as shown in Fig. 5).

2. Our model is mainly based on the work of Molnar et al. [3], but there are some problems when the BB algorithm (used in [3]) is applied to the model. This is explained in detail in our article. According to Laskari et al. [2], in most cases PSO algorithm outperforms BB algorithm; therefore, we decided to adopt PSO to overcome the shortcoming of BB algorithm.

3. Our article does not consider any optimization of structure, while in Romero and Jimenez [4] CSD space is used for each coefficient to reduce the complexity of structure. Our article does not consider any implementation information of the compensators, while in Romero and Jimenez [4] post place-and-rout information from FPGA-based implementations are reported. Our article does not consider any design of reconfigurable compensators, while in Romero and Jimenez [4] ad-hoc and reconfigurable compensators are reported.

The original article can be found online at https://doi.org/10.1007/s00034-018-0947-9.

Wei Yang

wyang@bjtu.edu.cn

Linsen Xu

linsenx@bjtu.edu.cn

Hongxian Tian

hxtian@bjtu.edu.cn

1 School of Electronic and Information Engineering, Beijing Jiaotong University, Beijing, China 


\section{References}

1. G.J. Dolecek, R.G. Baez, G.M. Salgado, J.M. de la Rosa, Novel multiplierless wideband comb compensator with high compensation capability. Circuits Syst. Signal Process. 36, 2031-2049 (2016)

2. E.C. Laskari, K.E. Parsopoulos, M.N. Vrahatis, Particle swarm optimization for integer programming, in Proceedings of the 2002 Congress on Evolutionary Computation. CEC'02 (Cat. No.02TH8600), Honolulu, HI, USA, vol. 2 (2002), pp. 1582-1587

3. G. Molnar, A. Dudarin, M. Vucic, Design of multiplierless CIC compensators based on maximum passband deviation, in 2017 40th International Convention on Information and Communication Technology, Electronics and Microelectronics (MIPRO), Opatija (2017), pp. 119-124

4. D.E.T. Romero, M.G.C. Jimenez, Efficient wide-band droop compensation for CIC filters: ad hoc and reconfigurable FIR architectures. Electron. Lett. 53(4), 228-229 (2017)

5. L. Xu, W. Yang, H. Tian, Design of wideband CIC compensator based on particle swarm optimization. Circuits Syst. Signal Process. 38(4), 1833-1846 (2019) (Published electronically September 26, 2018)

Publisher's Note Springer Nature remains neutral with regard to jurisdictional claims in published maps and institutional affiliations. 